\title{
Phenotypes and subphenotypes of delirium: a review of current categorisations and suggestions for progression
}

\author{
Emily M. L. Bowman ${ }^{1 *} \mathbb{D}$, Emma L. Cunningham', Valerie J. Page ${ }^{2}$ and Daniel F. McAuley ${ }^{3}$
}

\begin{abstract}
Delirium is a clinical syndrome occurring in heterogeneous patient populations. It affects $45-87 \%$ of critical care patients and is often associated with adverse outcomes including acquired dementia, institutionalisation, and death. Despite an exponential increase in delirium research in recent years, the pathophysiological mechanisms resulting in the clinical presentation of delirium are still hypotheses. Efforts have been made to categorise the delirium spectrum into clinically meaningful subgroups (subphenotypes), using psychomotor subtypes such as hypoactive, hyperactive, and mixed, for example, and also inflammatory and non-inflammatory delirium. Delirium remains, however, a constellation of symptoms resulting from a variety of risk factors and precipitants with currently no successful targeted pharmacological treatment. Identifying specific clinical and biological subphenotypes will greatly improve understanding of the relationship between the clinical symptoms and the putative pathways and thus risk factors, precipitants, natural history, and biological mechanism. This will facilitate risk factor mitigation, identification of potential methods for interventional studies, and informed patient and family counselling. Here, we review evidence to date and propose a framework to identify subphenotypes. Endotype identification may be done by clustering symptoms with their biological mechanism, which will facilitate research of targeted treatments. In order to achieve identification of delirium subphenotypes, the following steps must be taken: (1) robust records of symptoms must be kept at a clinical level. (2) Global collaboration must facilitate large, heterogeneous research cohorts. (3) Patients must be clustered for identification, validation, and mapping of subphenotype stability.
\end{abstract}

Keywords: Delirium, Inattention, Disorientation, Awareness, Encephalopathy, Pathophysiology, Phenotype, Subphenotype, Endotype, Psychomotor subtype

\section{Background \\ Phenotypes \\ Delirium}

Lötvall et al. define a phenotype as a set of clinical features in a group of patients who share a common syndrome or condition [1]. Delirium is a clinical syndrome, and therefore a phenotype, characterised by an acute and

\footnotetext{
*Correspondence: ebowman01@qub.ac.uk

${ }^{1}$ Centre for Public Health, Block B, Institute of Clinical Sciences, Royal

Victoria Hospital Site, Queen's University Belfast, Grosvenor Road, Belfast BT12 6BA, Northern Ireland

Full list of author information is available at the end of the article
}

fluctuating alteration in awareness and cognition resulting from pathophysiological disruption, which may be multifactorial [2-4]. It expresses as a range of symptoms with varying severity and course, affecting patient populations of all ages, but occurring most frequently where patients' brains are vulnerable and insults severe [3]. A 2020 systematic review and meta-analysis found the occurrence of delirium in the general medical population to be $23 \%$, but incidence varies depending on clinical setting and the diagnostic criteria used [5]. The incidence of delirium in the intensive care unit (ICU) ranges from 45 to $87 \%$ [6-8].

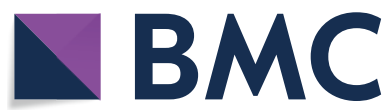

(c) The Author(s) 2021. Open Access This article is licensed under a Creative Commons Attribution 4.0 International License, which permits use, sharing, adaptation, distribution and reproduction in any medium or format, as long as you give appropriate credit to the original author(s) and the source, provide a link to the Creative Commons licence, and indicate if changes were made. The images or other third party material in this article are included in the article's Creative Commons licence, unless indicated otherwise in a credit line to the material. If material is not included in the article's Creative Commons licence and your intended use is not permitted by statutory regulation or exceeds the permitted use, you will need to obtain permission directly from the copyright holder. To view a copy of this licence, visit http://creativecommons.org/licenses/by/4.0/. The Creative Commons Public Domain Dedication waiver (http://creativeco mmons.org/publicdomain/zero/1.0/) applies to the data made available in this article, unless otherwise stated in a credit line to the data. 
Despite an exponential rise in delirium research, understanding of the pathophysiological processes underlying delirium remains low [9]. Regardless of cause, delirium presents as a reasonably common syndrome, particularly when it results from direct or indirect brain injury, but progress is being hindered by a lack of categorical organisation. Robust description which adequately reflects the severity spectrum of the syndrome, outcomes of ranging importance, and the various feasible preventative and management strategies is required [10]. Classifying all delirium presentations under one umbrella term may therefore be hindering proper advancement [11]. There are currently no systematic reviews or articles investigating delirium subphenotypes.

The terminology overlap of delirium and acute encephalopathy has recently been under scrutiny $[4,12]$. Acute encephalopathy describes a pathobiological brain process, presenting clinically as subsyndromal delirium, delirium, or coma [12]. The term 'delirium' facilitates patient-centred focus allowing screening, preventative measures, and psychological maintenance; however, this clinical phenotype does not account for underlying aetiologies [12]. Conversely, use of 'acute encephalopathy' defines cause and pathophysiology, but is ineffective for cases of ambiguous or unknown cause, or for patients whose delirium cause is historical or irreversible [12]. Recent recommendations are against using the terms 'acute confusional states', 'brain dysfunction', 'brain failure', and 'altered mental status' [4]. However, any remaining segregation of the literature of delirium and acute encephalopathy could be hindering optimal clinical management [4]. Oldham and Holloway suggest an integrated model where delirium is considered a clinical diagnosis, with encephalopathy used to describe underlying pathways, and the term delirium disorder combining both aspects [12].

\section{Subsyndromal delirium}

Subsyndromal delirium is also a phenotype, described in 1996 as a condition falling on a continuum between no delirium and DSM-defined delirium [13]. Currently, DSM-5 defines subsyndromal delirium as an attenuated delirium syndrome, which may be challenging to distinguish from mild delirium [14]. It describes symptoms that do not fulfil complete criteria for delirium diagnosis, without specifying which symptoms are present [15-17]. Subsyndromal delirium was investigated in elderly medical inpatients by Cole et al. in 2003 [15] and identified in the critical care setting by Ouimet et al. in 2007 [16]. The current volume of subsyndromal delirium literature is lacking; therefore, a clear conclusion about its association with clinical outcomes in the ICU is impaired. It is currently unknown whether identifying subphenotypes of subsyndromal delirium would be practically or clinically useful [18].

Subsyndromal delirium may be considered as part of a spectrum of delirium severity, when measuring the core diagnostic features [19]. Delirium severity is associated with greater length of hospital stay, 6-month mortality, and higher cost of care [20]. Therefore, these severity ratings are powerful in clinical care, alongside prognosis, and research advancement [21]. A 2019 systematic review found that there are 42 assessment tools for delirium severity and identified 6 of these as high quality, including the Confusion Assessment Method (CAM), Confusional State Examination, Delirium-O-Meter, Delirium Observation Scale, Delirium Rating Scale, and Memorial Delirium Assessment Scale [22]. In critical care, CAM-ICU-7 is often used to measure delirium severity. It measures delirium as not present with a score of 0 , subsyndromal $1-2$, mild to moderate with a score of $3-5$ or severe with $6-7$. Of note, individuals experiencing coma receive a score of 7 [23].

\section{Aims}

We propose building on the existing delirium categorisation framework by identifying potential methods for the integration of the differing delirium phenotypes, and its underlying putative pathways.

The potential application of subgrouping definitions to delirium is displayed in Fig. 1. This may be done by identifying separate 'clinical' subphenotypes, in symptom clusters, and mechanistic subphenotypes, incorporating the pathophysiology of delirium, as shown in Table 1 . Integrating these subphenotypes would present an endotype, as shown in Table 1 . The recent rise in novel techniques such as genomics, transcriptomics, proteomics, and metabolomics, alongside new tools for data analysis, has allowed increased identification of subgroups of disease, that is subphenotypes [24]. This review aims to highlight the potential alignment of clinical and biological subphenotypes of delirium and suggest how delirium research could benefit from this nomenclature, and to provoke discussion on the subject. We summarise advances in the identification of delirium subphenotypes from various researchers, discussing the implications of these findings on future studies and clinical application, identifying potential barriers in translation to clinical practice, and discussing approaches to overcome these. Pairing the correlation between these subphenotypes may improve knowledge and ability to develop effective delirium treatments. Our framework conveys that delirium is a phenotype, which may be viably categorised into subphenotypes based on one or more clinical or biological traits. Identification of the most suitable subphenotypes may be done by keeping robust and detailed 


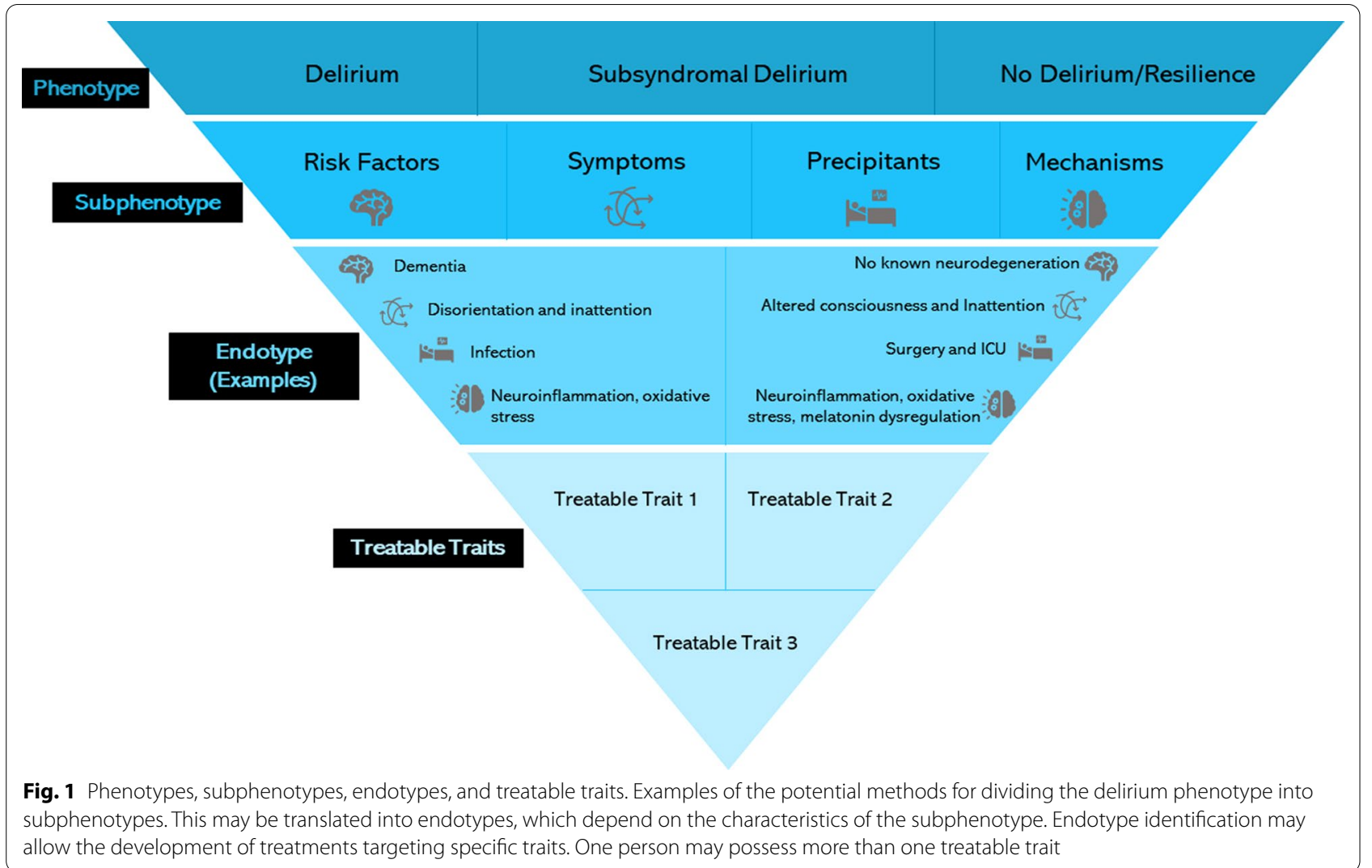

Table 1 A table displaying the definitions of phenotype, subphenotype, endotype, and treatable traits, as described by Lötvall et al. [1]

\begin{tabular}{|c|c|c|}
\hline Term & Definition & Potential application to delirium \\
\hline Phenotype & $\begin{array}{l}\text { A set of clinical features in a group of patients who share a com- } \\
\text { mon syndrome or condition. }\end{array}$ & $\begin{array}{l}\text { Altered cognition } \\
\text { Inattention } \\
\text { Altered awareness } \\
\text { Disorientation }\end{array}$ \\
\hline Subphenotype & $\begin{array}{l}\text { A set of features in a group of patients who share a phenotype. } \\
\text { Includes shared risk factors, traits, diagnostic features, expression } \\
\text { markers, mortality risk, or treatment response-which distin- } \\
\text { guishes the group from other patients with the same phenotype. }\end{array}$ & $\begin{array}{l}\text { Clinical } \\
\text { Shared risk quantification } \\
\text { Shared precipitants } \\
\text { Specific symptoms, e.g. inattention, agitation } \\
\text { Delirium duration } \\
\text { Diagnostic features } \\
\text { Defined by pathophysiology } \\
\text { Prominent mechanism } \\
\text { Inflammatory/non-inflammatory } \\
\text { Melatonin levels } \\
\text { Neurotransmitter presence } \\
\text { Network connectivity extent } \\
\text { Presence of oxidative stress }\end{array}$ \\
\hline Endotype & $\begin{array}{l}\text { A distinct biological mechanism of disease which is often associ- } \\
\text { ated with an anticipated clinical course, shared by a patient } \\
\text { subgroup. }\end{array}$ & $\begin{array}{l}\text { Associations between biological putative pathways of delirium } \\
\text { and the clinical symptoms which occur as a result }\end{array}$ \\
\hline Treatable traits & $\begin{array}{l}\text { Subgroup characteristics which may be successfully targeted by } \\
\text { an intervention. }\end{array}$ & $\begin{array}{l}\text { Decisions and development of the best course of action for } \\
\text { treatment- } \\
\text { Treating symptoms } \\
\text { Treating the mechanisms which express the symptoms } \\
\text { A combination of both }\end{array}$ \\
\hline
\end{tabular}

The potential applications of these definitions to delirium are listed, where the phenotype describes the most common clinical domains. Potential subphenotyping methods may be divided by clinical features and by pathophysiological hypotheses, and the endotype is a hybrid between these. Future treatable traits will be decided once the most effective methods are determined. It is important to note that this is a suggested framework for categorisation 
records in many delirium studies, so cluster analysis can be completed and replicated in both homogenous and heterogeneous cohorts. Consequent identification of endotypes, and therefore treatable traits, forms the final layer of this framework.

\section{Subphenotypes of delirium}

A subphenotype is a set of features in a group of patients who share a phenotype [1]. The subphenotype may include shared risk factors, traits, diagnostic features, expression markers, mortality risk or treatment response, distinguishing the group from other patients with the same phenotype [1]. The potential means of subphenotyping delirium are displayed in Table 1.

\section{Clinical subphenotypes}

The most common method of subdividing the delirium population is currently by psychomotor subtype. Lipowski first described the hypoactive and hyperactive psychomotor subtypes in 1983 [25], adding the mixed subtype in 1990 [10]. A 'no subtype' category exists for patients without psychomotor disturbance [26]. The incidence, severity, and extent of fluctuation observed in the psychomotor subtypes vary; however, the hypoactive and mixed psychomotor subtypes tend to confer worse outcomes and consume more medical resources [3, 27-31]. A recent systematic review of ICU studies reported that the heterogeneity in reporting and methodological quality is limiting robust assessment of outcome differences across subtypes [32].

The delirium traits expressed in the psychomotor subgroups are also specific [28, 33, 34]. In hypoactive delirium, speech is quiet, slow, and less, and the patient may be apathetic, withdrawn, have hypersomnolence, decreased activity, awareness, and alertness, and may experience perceptual disturbances [33, 35]. In hyperactive delirium, the patient may speak louder, faster, and more often. Their actions are faster and less controlled, with increased activity and wandering. There is increased awareness, alertness, restlessness, fear, and higher likelihood of hallucinations and euphoria than in hypoactive delirium. The mixed psychomotor subtype expresses as a transient combination of symptoms from both hyperactive delirium and hypoactive delirium [28]. Further subtyping of psychomotor subtypes has been suggested by severity correlating with outcomes, for example, hypoactive mild, hypoactive severe, mixed, and hyperactive [36]. Hypoactive delirium is seemingly more common than the hyperactive subtype, but the ratio of expressed subtypes differs between studies, with hypoactive delirium occurring in $28-56 \%$ hyperactive in $10-47 \%$ [35, 37, 38]. Of note, the psychomotor subtype may vary throughout a patients' hospital stay [37]. In adult survivors of critical illness, longer durations of hypoactive delirium have been associated with a small increase in difficulty completing essential activities of daily life, which was not observed in hyperactive cases [39]. Systematic reviews have explored the incidence of delirium psychomotor subtypes, as well as their risk factors and outcomes $[32,40]$. A 2018 systematic review found that 2,080 of 4,550 delirious patients in ICU experienced the hypoactive subtype, making it the most common subtype [40]. However, to our knowledge, there has not been a systematic review conducted exploring the incidence of specific clinical symptoms in various clinical settings, recorded independently from psychomotor subtype. The authors are currently planning a systematic review to fill this research gap.

Steering away from the use of psychomotor subtypes for delirium categorisation would allow identification of more focussed, specific subphenotypes, widening the opportunity for linking precipitants with the syndrome, with the aim of identifying clusters.

Over fifty delirium assessment tools exist, targeting identification of key clinical features by a combination of interview, observation, history, and cognitive tests [4143]. Delirium duration and rate of disappearance assessment also vary between patients and clinical settings [44]. The curve of delirium disappearance can be established by plotting delirium cases against time, therefore displaying its fluctuation and resolution [44]. A recent study aimed to assess delirium trajectory by integrating severity and duration, describing five distinct delirium 'trajectories', or dynamic symptom phenotypes [19]. Patient membership of these phenotypes predicted 30-day mortality [19]. Therefore, subphenotyping by severity and duration of delirium may aid in outcome prediction.

Clinically, classification of delirium by the presence, absence, or severity of symptoms might allow establishment of relationships between precipitants, risk factors, pathophysiology, and their effects. Different symptom domains may result in ranging prognosis; however, this is an area requiring more studies to identify the scale of this problem. A recent systematic review found that higher mortality levels are associated with presence of altered arousal and inattention during delirium episodes, compared to normal arousal or attentional levels in people with or without delirium [45]. Defined delirium symptom domains in the form of subphenotypes may aid in outcome prediction and treatment stratification [45]. Challenge lies in measuring these symptom domains.

\section{Precipitant subphenotypes}

Classifying delirium by its insults or indicators of acute brain injury has been explored by Girard et al., 2018, where delirium was classified as hypoxic, septic, 
sedative-associated, metabolic, or unclassified [46]. A large proportion of the unclassified delirium cases in this study experienced worse long-term cognitive outcomes than the other delirium phenotypes, which may represent an unidentified phenotype or an indication of persistent brain injury [46]. Other delirium-related insults include injury, surgery, CNS disorder, nutritional or hydration deficiencies, sleep deprivation, pain, toxin exposure, drug toxicity, anaesthesia, polypharmacy, and severe illness or medical conditions [47]. Often, multiple risk factors exist dependently, or risk factors may be absent or not identified before delirium presentation [46].

Precipitating risk factors are often setting specific. For example, reduced sleep quality is common in the ICU [48], and associated with delirium [49]. A quality improvement process designed to feasibly promote sleep in critical care has been associated with reductions in night-time noise levels, delirium, and coma [50-52]. This process may be conducted stepwise, beginning with disturbance reduction, moving to non-pharmacological methods, and then adding pharmacological aid for those patients whom did not show sleep improvement after the first two stages [50].

\section{Risk factor subphenotypes}

Predisposing and precipitating risk factors for delirium often coexist. This interrelationship depends on patient vulnerability and the extent of harmfulness of the insult(s) leading to delirium presentation [53]. For example, delirium may express differently in those who are already cognitively impaired, as a lesser insult is needed for delirium precipitation, in comparison with those who are cognitively intact. Table 2 summarises the most common risk factors for delirium in general medicine, and the additional factors to be considered in post-operative and intensive care unit (ICU) settings [10, 43, 54-60]. Effects from pro-cognitive factors, which promote healthy cognition, may also influence expression [12]. Application of predisposing and precipitating risk factors to the description of delirium subphenotypes would significantly increase understanding of how symptoms might be associated with aetiologies and guide research into delirium's pathophysiological mechanisms. Robust recording and extensive testing of the presence of risk factors are required, alongside consideration for unknown or unidentified risk factors.

Identification of biomarkers in cerebrospinal fluid (CSF) or blood plasma may aid in identification of patients who are most at risk of developing delirium, for example, pre-operatively [61, 62]. Electro-encephalopathy (EEG) is also a useful biomarker for delirium, both in identifying pre-operative vulnerability and active delirium processes, especially in populations which are difficult to assess, like ICU [63].

\section{Mechanisms}

Classification of delirium based on expression markers or biological data may provide insight into its underlying mechanisms, potentially leading to more ambitious targeted treatments which are not possible with reliance on classification by clinical traits only. At least six neuropathophysiological hypotheses, which remain poorly

Table 2 Predisposing and precipitating risk factors in the general medical, post-operative, and ICU settings [10, 43, 54-60]

\begin{tabular}{|c|c|c|c|}
\hline & General medicine & Additional operative risks & Additional ICU risks \\
\hline Predisposing risk factors & $\begin{array}{l}\text { Older age } \\
\text { Low daily activity levels } \\
\text { Immobility } \\
\text { Sensory impairment } \\
\text { Low levels of education } \\
\text { Malnutrition } \\
\text { Pre-existent cognitive impairment } \\
\text { Frailty } \\
\text { Comorbidities } \\
\text { Alcohol consumption } \\
\text { Visual/Hearing impairment }\end{array}$ & $\begin{array}{l}\text { Cerebral disease } \\
\text { Chronic diseases: renal, cardiac, } \\
\text { hepatic, or pulmonary } \\
\text { Alcohol/sedative-hypnotics addiction } \\
\text { History of delirium/functional psy- } \\
\text { chosis } \\
\text { Depression } \\
\text { Vitamin deficiency } \\
\text { Seizures or porphyria }\end{array}$ & $\begin{array}{l}\text { Higher illness severity } \\
\text { Unexpected hospital admission }\end{array}$ \\
\hline Precipitating risk factors & $\begin{array}{l}\text { Acute medical illness } \\
\text { Fractures } \\
\text { Head injury } \\
\text { Trauma } \\
\text { Surgery } \\
\text { Psychological stress } \\
\text { Drug use/withdrawal } \\
\text { Urinary catheterisation } \\
\text { Longer hospital stay }\end{array}$ & $\begin{array}{l}\text { Drug intoxication/anaesthesia } \\
\text { Metabolic disturbance } \\
\text { Hemodynamic disturbance } \\
\text { Respiratory disorders } \\
\text { Infection } \\
\text { Acute cerebral disorder } \\
\text { Alcohol/sedative withdrawal } \\
\text { Intraoperative/post-operative: } \\
\text { Sleep deprivation } \\
\text { Immobilisation } \\
\text { Restraints }\end{array}$ & $\begin{array}{l}\text { Mechanical ventilation (and } \\
\text { duration of ventilation) } \\
\text { Sepsis } \\
\text { Opioids } \\
\text { Polypharmacy } \\
\text { Circadian rhythm disruption } \\
\text { Deep sedation } \\
\text { Organ failure }\end{array}$ \\
\hline
\end{tabular}


understood, have been proposed to precipitate delirium [64]. These theories are complementary and accumulative, rather than competitive [64]. They may translate into potential subphenotypes defined by underlying mechanism. Other phenotyping successes, such as that of asthma, have endotyped groups based on the pathophysiological processes leading to the development and progression of disease and treatment responses [65]. This allows further treatment research to target the relevant patient groups [65]. Applying similar methods to delirium, using well-characterised cohorts with appropriate representation of the spectrum of the syndrome, and incorporating bioinformatics, may see phenotyping success, and eventual development of effective treatments [66]. The neuroinflammation hypothesis may allow for categorisation into inflammatory or neuroinflammatory, and non-inflammatory delirium, as the biomarkers may differ depending on presence of inflammation [67, 68]. High levels of C-reactive protein (CRP), a marker of acute inflammatory response, are independently associated with delirium [69]. In ICU patients, higher levels of CRP and procalcitonin are associated with a longer period of delirium or coma [70]. Additional potential biomarkers for neuroinflammation are plasma proinflammatory cytokines including tumour necrosis factor (TNF- $\alpha$ ), cortisol, S100B-protein, and interleukins (IL$1 \beta$, IL-2, IL-6, IL-8, IL-12) [71-77]. Cytokine levels are measured peripherally from the blood, but brain cytokine levels cannot be quantified readily and low accessibility to the central nervous system restricts this research [78]. A 2008 cross-sectional study investigating pro-inflammatory cytokine levels in elderly patients with hip fractures found that plasma IL-6 and IL-8 levels were higher in patients who developed delirium post-operatively [78]. A 2014 study suggested that IL- $1 \beta$ production in the CNS may be an indicator of early event in the pathogenesis cascade of delirium [79]. However, trace IL levels in CSF and the consequent reliability on extrapolation decrease the reliability of these tests [79]. IL-10 is a marker for non-inflamed patients [67]. It has also been hypothesised that repeated endogenous glucocorticoid release in response to stress contributes to delirium development [80].

The neuronal ageing hypothesis may be observed by examination of brain volume using tools such as molecular resonance imaging which may aid in subphenotype identification [81]. This is due to the effects of age in decreasing cerebral blood flow, capillary density, and therefore diminishing brain volume [82, 83]. In ICU patients, long delirium episodes are associated with diminished brain volume at hospital discharge and three months after, indicating neural atrophy [84]. However, without premorbid imaging, it cannot be determined whether this relationship is cause or effect. Volume loss is concentrated in the hippocampus and superior frontal lobe which are important in memory and behaviour control [84]. White matter disruption was also been associated with deteriorating cognition, which may affect attention, working memory, and executive function [85]. Increased levels of the neuronal injury fluid biomarker, neurofilament light (NfL), are also associated with delirium occurrence, in a dose-dependent relationship.

The oxidative stress hypothesis is derived from evidence of increased hippocampal reactive oxygen species (ROS) associated with delirium during in vivo study [86, 87]. Alternatively, hippocampal levels of superoxide dismutase (SOD), glutathione peroxidase (GSH-Px), and catalase (CAT), species involved in the oxidative stress process, are decreased during delirium [88]. Therefore, quantifying SOD, GSH-Px, and CAT concentration may aid in the identification of pathophysiology. Glucose metabolic dysfunction may also contribute to delirium occurrence [89].

The neurotransmitter hypothesis incorporates the serotonergic, dopaminergic, and cholinergic systems [90]. Limitation of tetrahydrobiopterin $\left(\mathrm{BH}_{4}\right)-\mathrm{a}$ cofactor in serotonin, and dopamine production, has been associated with both Alzheimer's disease and delirium after elective cardiac surgery [90, 91]. Elevated anticholinergic activity is also positively correlated with higher delirium severity [92, 93].

The melatonin dysregulation hypothesis suggests that some of the difference in delirium symptoms could be associated with melatonin levels [94]. A prospective study of hospitalised patients in Israel found that patients with hyperactive delirium had lower levels of 6-sulphatoxymelatonin (6-SMT), the chief metabolite of melatonin, compared to hypoactive [94]. Sleep-wake cycle disruption observed in Alzheimer's disease is attributable to decreased levels of melatonin and disturbed circadian melatonin rhythm [95].

The network dysconnectivity hypothesis suggests that the clinically expressed symptoms of delirium may be attributable to disruption of functional networks in the brain and altered homeostasis of neural oscillation [96]. The default mode network (DMN) is a task-negative intrinsic connectivity network involving brain regions which increase their activity during the absence of a task [97]. Therefore, it is known as a 'task-negative' network, which is correlated with a 'task-positive' network, resulting in anticorrelation [97]. The DMN incorporates the posterior cingulate cortex, medial temporal lobe, inferior temporal lobe, and inferior parietal lobule [97]. For example, a 2019 study of differences in the resting-state brain network before and during an episode of delirium found a connectivity between the posterior cingulate 
cortex and negatively correlated pre-frontal cortex during delirium [98]. It also found reduced connectivity between the subcortical regions, indicating that to maintain consciousness, stable cholinergic, and dopaminergic neurotransmission is required [98]. Reduced network anticorrelation may explain the attention deficit observed in delirium [99]. Neuronal network dysconnectivity is thought to be the final buffer in delirium, regardless of aetiology, where there is reduction in normal cognitive function [100]. This dysconnectivity might be a consequence of altered glucose metabolism [101]. The nature of this buffer, or which areas of the DMN are affected, may provide categorisation opportunity, but as the DMN varies with age, sex, and cognitive function, classifying 'normal' is challenging [102].

\section{Translation of subphenotypes into clinical practice} Challenges in understanding delirium, multimorbidity, and comparison in subphenotyping

Numerous challenges and limitations must be overcome to translate subphenotypes into clinical practice, involving understanding of delirium as a syndrome, study heterogeneity, multimorbidity, research efforts, and the unknowns of subphenotyping. These challenges are detailed in Table 3, alongside suggestions for overcoming said obstacles. An endotype is a distinct biological mechanism of disease which is often associated with an anticipated clinical course, shared by a patient subgroup [1]. Identification of delirium endotypes would integrate the clinical and biomarker-driven subphenotypes to create a hybrid description and open the possibility of targeted interventions of subgroup characteristics, that is, treatable traits [1]. The challenge of translating subphenotypes into endotypes may also be viewed as a strength of the proposed framework for future application, as new ideas, methods, and collaboration are welcomed, to aid in a research area which is still in its infancy. In the setting of precision medicine, the populations available to be studied will be smaller; therefore, global cooperation will enable research questions to be answered in a timely manner.

\section{Methods for subphenotype validation}

Shared mortality risk or treatment response of delirium clusters may demonstrate correlation between categorisation and outcomes. Non-pharmacological reduction of delirium risk involves several interventions centred around optimising physiology, promoting cognitive engagement and mobilisation [103, 104]. Demonstration that the categorisation of delirium subphenotypes correlates with outcomes may be done by monitoring response to interventions for improvement of orientation. These interventions may include: wearing glasses or hearing aids, mobilisation, pain control, involving relatives and minimising ward movement, could be used, to in a stepwise manner, to organise delirium into subphenotypes [104]. However, evidence of the effectiveness of these non-pharmacological methods in ICU is low and limited to randomised control trials [105]. Settingspecific interventions may also be considered, like sleep promotion in ICU, and avoidance of excessively deep anaesthesia post-operatively [104]. Use of pharmacological treatment in delirium including antipsychotic agents and anticholinesterase inhibitors has been investigated; however, currently none of these treatments are recommended for use $[104,106]$. To warrant categorisation by pharmacological treatment response, beneficial effects must first be proven. The extent of variation of outcome or treatment between each of the subphenotype groups remains to be seen. It is possible that some subphenotypes are more highly associated with dementia, institutionalisation, or death. When accounting for all subphenotypes in a population identified by DSM- 5 classification, the outcomes will be the same, but may vary between subphenotypes. This may allow targeted therapeutic interventions by analysing 'phenotype-dependant treatment response' [107]. The most effective methods of treatment vary between groups, holding potential to provide extensive opportunity for development of clinical protocol. For example, in Acute Respiratory Distress Syndrome (ARDS), differential treatment response has been shown between subphenotypes [108-110].

\section{Recommendations for future studies}

Assignment of subphenotypes of delirium must be a collaborative, global process. Recommendations on achieving this are detailed in Table 4, following guidelines previously suggested by Reddy et al., in the critical care setting [24], and deriving the key efforts required to overcome the challenges discussed in Table 3. In general, identifying aetiology of delirium is difficult and requires large, robust, and highly powered studies, and pre-delirium patients' brains are often vulnerable.

\section{Conclusion}

The identification of subphenotypes of delirium is a task which requires prioritising delirium as a syndrome worth vast clinical attention and research. The most viable subphenotyping approaches should be selected and methods for their translation to clinical practice created. Barriers in delirium diagnosis and heterogeneity of populations must be overcome on an international scale to allow precision and use of the most robust clustering techniques. This advancement will enable new levels in understanding of the underlying putative pathways by which the delirium phenotype arises. We recommend eventual 


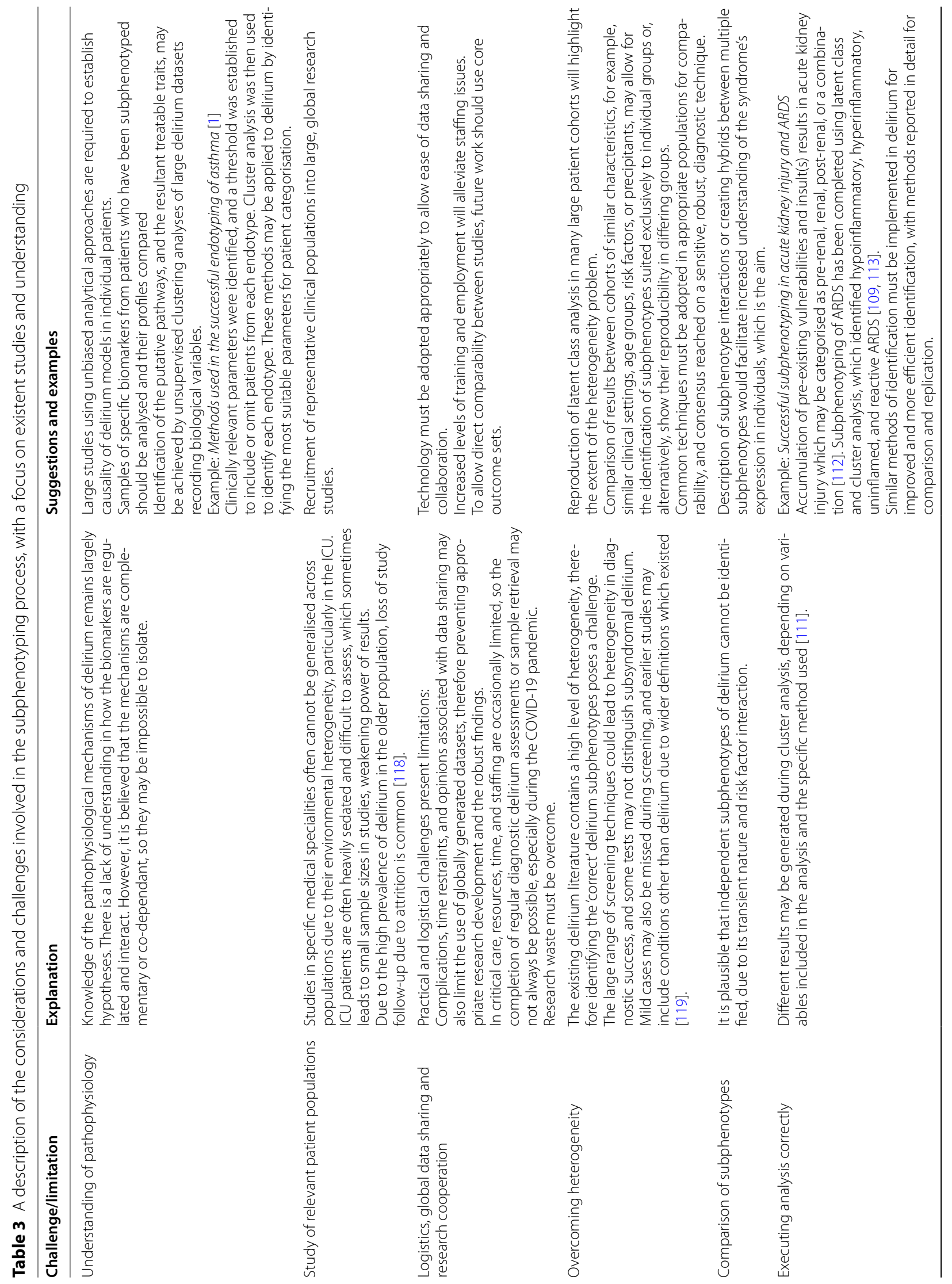




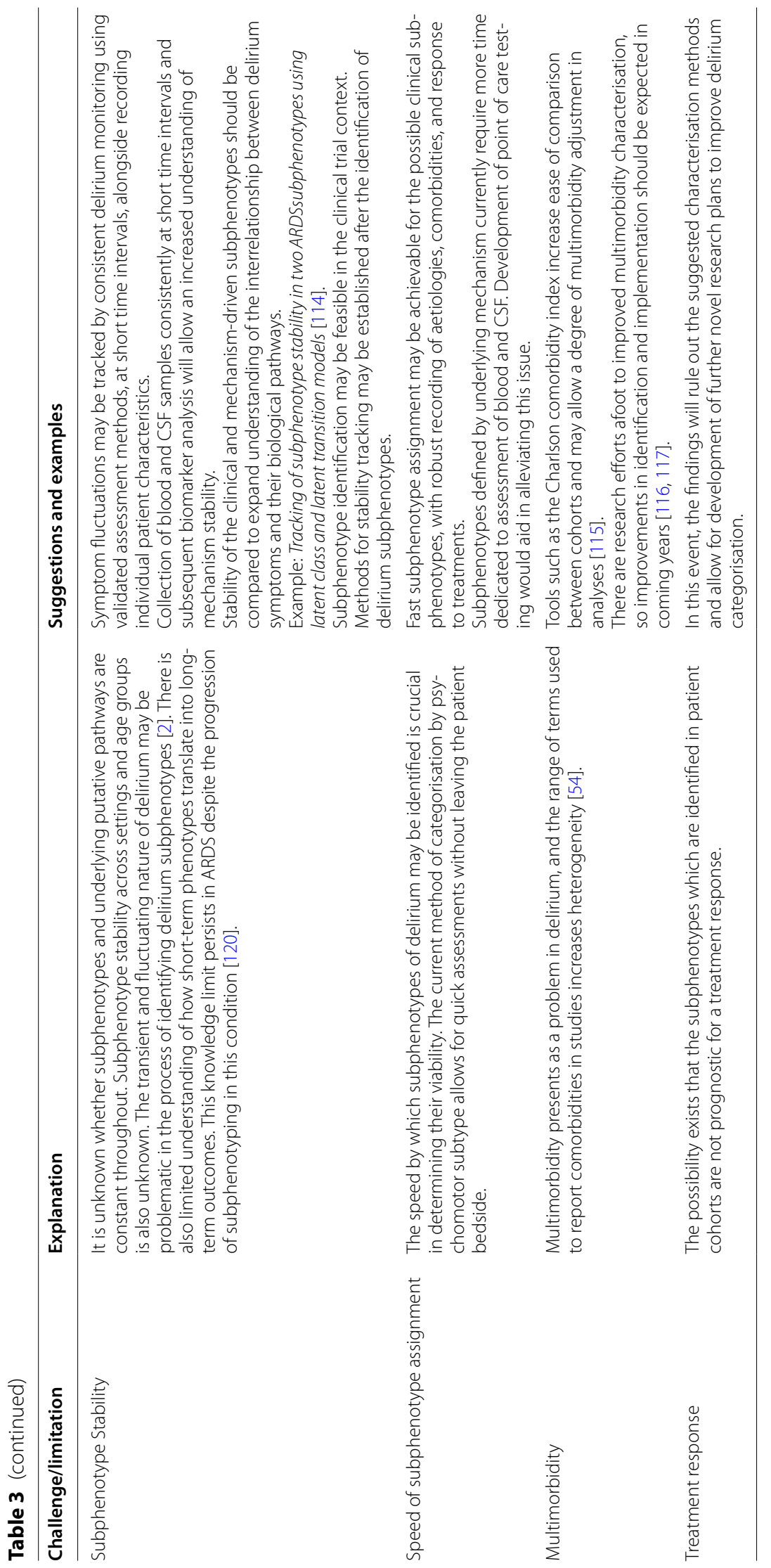


Table 4 Recommendations for research progression in subphenotype identification

Research recommendation
Establishment of subphenotype reproducibility and overlap
Establishment of subphenotype stability across clinical set-
tings and patient demographics

tings and patient demographics

Validation of subphenotyping strategies

\section{Actions required}

Use of large prospective studies with heterogeneous patient cohorts to validate subphenotypes and compare similar subphenotypes.

The prospective studies must exist of heterogeneous patient cohorts across multiple clinical settings. The studies should be repeated to assess subphenotypes which differ by severity and duration, and studies should also be repeated at multiple time points. Subphenotype-related biomarkers should be compared across various settings where appropriate.

Sharing of large datasets and algorithms between investigators, ideally by making data open access. Greater levels of cybersecurity required.

Emphasis on collaboration and involvement in publications. progression from subphenotypes to endotypes by creation of a biological-clinical subtype hybrid. This may be completed by identification of underlying mechanism clusters and their course alongside clinical expression. For definition of treatable traits, the mechanistic differences between the subphenotypes must be clarified to allow targeted treatment. Treatments or interventions may then be developed using in vitro and in vivo models and then tested prospectively to assess clinical value.

\section{Abbreviations \\ ICU: Intensive care unit; CAM: Confusion assessment method; CSF: Cerebrospi- nal fluid; EEG: Electro-encephalopathy; TNF-a: Tumour necrosis factor; IL: Inter- leukin; CRP: C-reactive protein; ROS: Reactive oxygen species; SOD: Superoxide dismutase; GSH-Px: Glutathione peroxidase; CAT: Catalase; $\mathrm{BH}_{4}$ : Tetrahydrobi- opterin; 6-SMT: 6-Sulphatoxymelatonin; DMN: Default mode network; ARDS: Acute respiratory distress syndrome.}

\section{Acknowledgements}

Not applicable.

\section{Authors' contributions}

EB drafted the manuscript with major contribution from ELC. DM and VP substantially revised the manuscript, and all authors read and approved the final manuscript.

\section{Funding}

EB is a PhD student at Queen's University Belfast, funded by the Department for the Economy (DfE), Northern Ireland.

\section{Availability of data and materials \\ Not applicable.}

\section{Declarations}

Ethics approval and consent to participate

Not applicable.

\section{Consent for publication}

Not applicable.

\section{Competing interests}

The authors declare that they have no competing interests.

\begin{abstract}
Author details
${ }^{1}$ Centre for Public Health, Block B, Institute of Clinical Sciences, Royal Victoria Hospital Site, Queen's University Belfast, Grosvenor Road, Belfast BT12 6BA, Northern Ireland. 'Department of Anaesthetics, Watford General Hospital, Vicarage Road, Watford WD19 4DZ, UK. ${ }^{3}$ Centre for Experimental Medicine, Wellcome-Wolfson Institute for Experimental Medicine, Queen's University Belfast, 97 Lisburn Road, Belfast BT9 7BL, Northern Ireland.
\end{abstract}

Received: 21 May 2021 Accepted: 31 August 2021

Published online: 15 September 2021

\section{References}

1. Lötvall J, Akdis CA, Bacharier LB, et al. Asthma endotypes: a new approach to classification of disease entities within the asthma syndrome. J Allergy Clin Immunol. 2011;127:355-60.

2. Thom RP, Levy-Carrick NC, Bui M, et al. Delirium. Am J Psychiatry. 2019;176:785-93.

3. Kim S-Y, Kim J-M, Kim S-W, et al. Do the phenotypes of symptom fluctuation differ among motor subtypes in patients with delirium? J Pain Symptom Manag. 2018:56:667-77.

4. Slooter AJC, Otte WM, Devlin JW, et al. Updated nomenclature of delirium and acute encephalopathy: statement of ten Societies. Intensive Care Med. 2020;46:1020-2.

5. Gibb K, Seeley A, Quinn T, et al. The consistent burden in published estimates of delirium occurrence in medical inpatients over four decades: a systematic review and meta-analysis study. Age Ageing. 2020:49:352-60.

6. Roberts B, Rickard CM, Rajbhandari D, et al. Multicentre study of delirium in ICU patients using a simple screening tool. Aust Crit care Off J Confed Aust Crit Care Nurses 2005;18:6, 8-9, 11-4 passim.

7. Thomason JWW, Shintani A, Peterson JF, et al. Intensive care unit delirium is an independent predictor of longer hospital stay: a prospective analysis of 261 non-ventilated patients. Crit Care. 2005;9:R375-81.

8. Ely EW, Margolin R, Francis J, et al. Evaluation of delirium in critically ill patients: validation of the confusion assessment method for the intensive care unit (CAM-ICU). Crit Care Med. 2001;29:1370-9.

9. Grover S, Sharma A, Aggarwal M, et al. Comparison of symptoms of delirium across various motoric subtypes. Psychiatry Clin Neurosci. 2014;68:283-91.

10. Lipowski ZJ. Delirium: acute confusional states. New York: Oxford University Press; 1990.

11. Oldham MA, Flaherty JH, Maldonado JR. Refining delirium: a transtheoretical model of delirium disorder with preliminary neurophysiologic subtypes. Am J Geriatr Psychiatry. 2018;26:913-24.

12. Oldham MA, Holloway RG. Delirium disorder. Neurology. 2020;95:173-8.

13. Levkoff SE, Liptzin B, Cleary PD, et al. Subsyndromal delirium. Am J Geriatr Psychiatry. 1996;4:320-9. 
14. Meagher DJ, Morandi A, Inouye SK, et al. Concordance between DSM-IV and DSM-5 criteria for delirium diagnosis in a pooled database of 768 prospectively evaluated patients using the delirium rating scalerevised-98. BMC Med. 2014;12:164.

15. Cole M, McCusker J, Dendukuri N, et al. The prognostic significance of subsyndromal delirium in elderly medical inpatients. J Am Geriatr Soc. 2003;51:754-60.

16. Ouimet S, Riker R, Bergeon N, et al. Subsyndromal delirium in the ICU: evidence for a disease spectrum. Intensive Care Med. 2007:33:1007-13.

17. Bastos AS, Beccaria LM, da Silva DC, et al. Identification of delirium and subsyndromal delirium in intensive care patients. Rev Bras Enferm. 2019;72:463-7.

18. Serafim RB, Soares M, Bozza FA, et al. Outcomes of subsyndromal delirium in ICU: a systematic review and meta-analysis. Crit Care. 2017;21:179.

19. Lindroth $\mathrm{H}$, Khan BA, Carpenter JS, et al. Delirium severity trajectories and outcomes in ICU patients. Defining a dynamic symptom phenotype. Ann Am Thorac Soc. 2020;17:1094-103.

20. Ely EW, Shintani A, Truman B, et al. Delirium as a predictor of mortality in mechanically ventilated patients in the intensive care unit. JAMA. 2004;291:1753-62.

21. Eubank KJ, Covinsky KE. Delirium severity in the hospitalized patient: time to pay attention. Ann Intern Med. 2014;160:574-5.

22. Jones RN, Cizginer S, Pavlech L, et al. Assessment of instruments for measurement of delirium severity: a systematic review. JAMA Intern Med. 2019;179:231-9.

23. Khan BA, Perkins AJ, Gao S, et al. The confusion assessment method for the ICU-7 delirium severity scale: a novel delirium severity instrument for use in the ICU. Crit Care Med. 2017;45:851-7.

24. Reddy K, Sinha P, O'Kane CM, et al. Subphenotypes in critical care: translation into clinical practice. Lancet Respir Med. 2020;8:631-43.

25. Lipowski ZJ. Transient cognitive disorders (delirium, acute confusional states) in the elderly. Am J Psychiatry. 1983;140:1426-36.

26. Liptzin B, Levkoff SE. An empirical study of delirium subtypes. Br J Psychiatry. 1992;161:843-5.

27. Jackson TA, Wilson D, Richardson S, et al. Predicting outcome in older hospital patients with delirium: a systematic literature review. Int J Geriatr Psychiatry. 2016;31:392-9.

28. Oh S-T, Park JY. Postoperative delirium. Korean J Anesthesiol. 2019;72:4-12.

29. Fialho Silva IT, Assis Lopes P, Timotio Almeida T, et al. Impact of delirium and its motor subtypes on stroke outcomes. Stroke. 2021;52:1322-9.

30. Hayhurst CJ, Marra A, Han JH, et al. Association of hypoactive and hyperactive delirium with cognitive function after critical illness. Crit Care Med. 2020;48:e480-8.

31. Zhang R, Bai L, Han X, et al. Incidence, characteristics, and outcomes of delirium in patients with noninvasive ventilation: a prospective observational study. BMC Pulm Med. 2021;21:157.

32. Krewulak KD, Stelfox HT, Ely EW, et al. Risk factors and outcomes among delirium subtypes in adult ICUs: a systematic review. J Crit Care. 2020;56:257-64

33. Maldonado JR. Acute brain failure: pathophysiology, diagnosis, management, and sequelae of delirium. Crit Care Clin. 2017;33:461-519.

34. Meagher D. Motor subtypes of delirium: past, present and future. Int Rev Psychiatry. 2009;21:59-73.

35. Boettger S, Breitbart W. Phenomenology of the subtypes of delirium: phenomenological differences between hyperactive and hypoactive delirium. Palliat Support Care. 2011;9:129-35.

36. Yang FM, Marcantonio ER, Inouye SK, et al. Phenomenological subtypes of delirium in older persons: patterns, prevalence, and prognosis. Psychosomatics. 2009;50:248-54.

37. Meagher DJ, Leonard M, Donnelly S, et al. A longitudinal study of motor subtypes in delirium: relationship with other phenomenology, etiology, medication exposure and prognosis. J Psychosom Res. 2011;71:395-403.

38. Albrecht JS, Marcantonio ER, Roffey DM, et al. Stability of postoperative delirium psychomotor subtypes in individuals with hip fracture. J Am Geriatr Soc. 2015;63:970-6.

39. Rengel KF, Hayhurst CJ, Jackson JC, et al. Motoric subtypes of delirium and long-term functional and mental health outcomes in adults after critical illness. Crit Care Med. 2021. https://doi.org/10.1097/ccm.00000 00000004920.

40. Krewulak KD, Stelfox HT, Leigh JP, et al. Incidence and prevalence of delirium subtypes in an adult ICU: a systematic review and meta-analysis. Crit Care Med. 2018;46:2029-35.

41. Tieges Z, Evans JJ, Neufeld KJ, et al. The neuropsychology of delirium: advancing the science of delirium assessment. Int J Geriatr Psychiatry. 2018;33:1501-11.

42. De J, Wand APF. Delirium screening: a systematic review of delirium screening tools in hospitalized patients. Gerontologist. 2015;55:1079-99.

43. Wilson JE, Mart MF, Cunningham C, et al. Delirium. Nat Rev Dis Prim. 2020;6:90.

44. Manos PJ, Wu R. The duration of delirium in medical and postoperative patients referred for psychiatric consultation. Ann Clin psychiatry Off J Am Acad Clin Psychiatr. 1997;9:219-26.

45. Tieges Z, Quinn T, MacKenzie L, et al. Association between components of the delirium syndrome and outcomes in hospitalised adults: a systematic review and meta-analysis. BMC Geriatr. 2021;21:162.

46. Girard TD, Thompson JL, Pandharipande PP, et al. Clinical phenotypes of delirium during critical illness and severity of subsequent long-term cognitive impairment: a prospective cohort study. Lancet Respir Med. 2018;6:213-22.

47. Maldonado JR. Delirium pathophysiology: an updated hypothesis of the etiology of acute brain failure. Int J Geriatr Psychiatry. 2018;33:1428-57.

48. Freedman NS, Kotzer N, Schwab RJ. Patient perception of sleep quality and etiology of sleep disruption in the intensive care unit. Am J Respir Crit Care Med. 1999;159:1155-62.

49. Figueroa-Ramos MI, Arroyo-Novoa CM, Lee KA, et al. Sleep and delirium in ICU patients: a review of mechanisms and manifestations. Intensive Care Med. 2009;35:781-95.

50. Kamdar BB, King LM, Collop NA, et al. The effect of a quality improvement intervention on perceived sleep quality and cognition in a medical ICU. Crit Care Med. 2013;41:800-9.

51. Patel J, Baldwin J, Bunting P, et al. The effect of a multicomponent multidisciplinary bundle of interventions on sleep and delirium in medical and surgical intensive care patients. Anaesthesia. 2014;69:540-9.

52. Tonna JE, Dalton A, Presson AP, et al. The effect of a quality improvement intervention on sleep and delirium in critically ill patients in a surgical ICU. Chest. 2021. https://doi.org/10.1016/j.chest.2021.03.030.

53. Inouye SK, Charpentier PA. Precipitating factors for delirium in hospitalized elderly persons. Predictive model and interrelationship with baseline vulnerability. JAMA. 1996;275:852-7.

54. Ahmed S, Leurent B, Sampson EL. Risk factors for incident delirium among older people in acute hospital medical units: a systematic review and meta-analysis. Age Ageing. 2014;43:326-33.

55. Jones RN, Yang FM, Zhang Y, et al. Does educational attainment contribute to risk for delirium? A potential role for cognitive reserve. J Gerontol Ser A. 2006;61:1307-11.

56. Elie M, Cole MG, Primeau FJ, et al. Delirium risk factors in elderly hospitalized patients. J Gen Intern Med. 1998;13:204-12.

57. Voyer P, Cole MG, McCusker J, et al. Prevalence and symptoms of delirium superimposed on dementia. Clin Nurs Res. 2006;15:46-66.

58. Gual N, Morandi A, Pérez LM, et al. Risk factors and outcomes of delirium in older patients admitted to postacute care with and without dementia. Dement Geriatr Cogn Disord. 2018;45:121-9.

59. Kanova M, Sklienka P, Roman K, et al. Incidence and risk factors for delirium development in ICU patients - a prospective observational study. Biomed Pap Med Fac Univ Palacky Olomouc Czechoslov. 2017;161:187-96.

60. Jitapunkul S, Pillay I, Ebrahim S. Delirium in newly admitted elderly patients: a prospective study. QJM An Int J Med. 1992;83:307-14.

61. Pan X, Cunningham EL, Passmore AP, et al. Cerebrospinal fluid spermidine, glutamine and putrescine predict postoperative delirium following elective orthopaedic surgery. Sci Rep. 2019;9:4191.

62. Cunningham EL, McGuinness B, McAuley DF, et al. CSF beta-amyloid 1-42 concentration predicts delirium following elective arthroplasty surgery in an observational cohort study. Ann Surg. 2019;269:1200-5.

63. van der Kooi AW, Zaal IJ, Klijn FA, et al. Delirium detection using EEG: what and how to measure. Chest. 2015;147:94-101. 
64. Maldonado JR. Neuropathogenesis of delirium: review of current etiologic theories and common pathways. Am J Geriatr psychiatry Off J Am Assoc Geriatr Psychiatry. 2013;21:1190-222.

65. Page VJ. Does sedation related delirium matter? Lancet Respir Med. 2018;6:167-8

66. Levy BD, Noel PJ, Freemer MM, et al. Future research directions in asthma. An NHLBI working group report. Am J Respir Crit Care Med. 2015;192:1366-72.

67. van den Boogaard M, Kox M, Quinn KL, et al. Biomarkers associated with delirium in critically ill patients and their relation with long-term subjective cognitive dysfunction; indications for different pathways governing delirium in inflamed and noninflamed patients. Crit Care. 2011;15:R297-R297.

68. Cerejeira J, Firmino H, Vaz-Serra A, et al. The neuroinflammatory hypothesis of delirium. Acta Neuropathol. 2010;119:737-54.

69. Macdonald A, Adamis D, Treloar A, et al. C-reactive protein levels predict the incidence of delirium and recovery from it. Age Ageing. 2007:36:222-5.

70. McGrane S, Girard TD, Thompson JL, et al. Procalcitonin and C-reactive protein levels at admission as predictors of duration of acute brain dysfunction in critically ill patients. Crit Care. 2011;15:R78-R78.

71. Kurosawa S, Kato M. Anesthetics, immune cells, and immune responses. J Anesth. 2008;22:263-77.

72. Barton GM. A calculated response: control of inflammation by the innate immune system. J Clin Invest. 2008;118:413-20.

73. Bjornsson GL, Thorsteinsson L, Gudmundsson KO, et al. Inflammatory cytokines in relation to adrenal response following total hip replacement. Scand J Immunol. 2007;65:99-105

74. Liu P, Li Y, Wang X, et al. High serum interleukin-6 level is associated with increased risk of delirium in elderly patients after noncardiac surgery: a prospective cohort study. Chin Med J (Engl). 2013;126:3621-7.

75. van Munster BC, Bisschop PH, Zwinderman AH, et al. Cortisol, interleukins and S100B in delirium in the elderly. Brain Cogn. 2010;74:18-23.

76. de Rooij SE, van Munster BC, Korevaar JC, et al. Cytokines and acute phase response in delirium. J Psychosom Res. 2007;62:521-5.

77. MacLullich AMJ, Edelshain BT, Hall RJ, et al. Cerebrospinal fluid interleukin-8 levels are higher in people with hip fracture with perioperative delirium than in controls. J Am Geriat Soc. 2011:59:1151-3.

78. van Munster BC, Korevaar JC, Zwinderman AH, et al. Time-course of cytokines during delirium in elderly patients with hip fractures. J Am Geriatr Soc. 2008;56:1704-9.

79. Cape E, Hall RJ, van Munster BC, et al. Cerebrospinal fluid markers of neuroinflammation in delirium: a role for interleukin-1 $\beta$ in delirium after hip fracture. J Psychosom Res. 2014;77:219-25.

80. Hill AR, Spencer-Segal JL. Glucocorticoids and the brain after critical illness. Endocrinology. 2021. https://doi.org/10.1210/endocr/bqaa242.

81. Helms J, Kremer S, Merdji H, et al. Delirium and encephalopathy in severe COVID-19: a cohort analysis of ICU patients. Crit Care. 2020:24:491.

82. Diaz-Otero JM, Garver H, Fink GD, et al. Aging is associated with changes to the biomechanical properties of the posterior cerebral artery and parenchymal arterioles. Am J Physiol Heart Circ Physiol. 2016:310:H365-75.

83. Li Y, Choi WJ, Wei W, et al. Aging-associated changes in cerebral vasculature and blood flow as determined by quantitative optical coherence tomography angiography. Neurobiol Aging. 2018;70:148-59.

84. Gunther ML, Morandi A, Krauskopf E, et al. The association between brain volumes, delirium duration, and cognitive outcomes in intensive care unit survivors: the VISIONS cohort magnetic resonance imaging study*. Crit Care Med. 2012;40:2022-32.

85. Morandi A, Rogers BP, Gunther ML, et al. The relationship between delirium duration, white matter integrity, and cognitive impairment in intensive care unit survivors as determined by diffusion tensor imaging the VISIONS prospective cohort magnetic resonance imaging study* Crit Care Med. 2012;40:2182-9.

86. Pizzino G, Irrera N, Cucinotta $M$, et al. Oxidative stress: harms and benefits for human health. Oxid Med Cell Longev. 2017;2017:8416763.

87. Zhang J, Gao J, Guo G, et al. Anesthesia and surgery induce deliriumlike behavior in susceptible mice: the role of oxidative stress. Am J Transl Res. 2018;10:2435-44.
88. Karlidag R, Unal S, Sezer OH, et al. The role of oxidative stress in postoperative delirium. Gen Hosp Psychiatry. 2006;28:418-23.

89. Caplan GA, Haggstrom LR, Nelson JA, et al. [P4-504]: NOVEL UNIQUE PATTERN OF CEREBRAL GLUCOSE HYPOMETABOLISM SEEN ON 2-18F-FLUORO-2-DEOXYGLUCOSE POSITRON EMISSION TOMOGRAPHY IN DELIRIUM. Alzheimer's Dement. 2017;13:P1533-P1533.

90. Egberts A, Fekkes D, Wijnbeld EHA, et al. Disturbed serotonergic neurotransmission and oxidative stress in elderly patients with delirium Dement Geriatr Cogn Dis Extra. 2015:5:450-8.

91. Foxton RH, Land JM, Heales SJR. Tetrahydrobiopterin availability in Parkinson's and Alzheimer's disease; potential pathogenic mechanisms. Neurochem Res. 2007;32:751-6.

92. Hshieh TT, Fong TG, Marcantonio ER, et al. Cholinergic deficiency hypothesis in delirium: a synthesis of current evidence. J Gerontol Ser A 2008;63:764-72

93. Slooter AJC, Van De Leur RR, Zaal IJ. Chapter 25-Delirium in critically ill patients. In: Wijdicks EFM, editor. Critical care neurology part II. Amsterdam: Elsevier; 2017. p. 449-66.

94. Balan S, Leibovitz A, Zila SO, et al. The relation between the clinical subtypes of delirium and the urinary level of 6-SMT. J Neuropsychiatry Clin Neurosci. 2003;15:363-6.

95. Wu Y-H, Feenstra MGP, Zhou J-N, et al. Molecular changes underlying reduced pineal melatonin levels in Alzheimer disease: alterations in preclinical and clinical stages. J Clin Endocrinol Metab. 2003;88:5898-906.

96. Fleischmann $\mathrm{R}$, Traenkner $\mathrm{S}$, Kraft A, et al. Delirium is associated with frequency band specific dysconnectivity in intrinsic connectivity networks: preliminary evidence from a large retrospective pilot casecontrol study. Pilot feasibility Stud. 2019;5:2.

97. Yıldırım E, Soncu BE. Default mode network connectivity in alzheimers disease. Turk Psikiyatri Derg. 2019;30:279-86.

98. Oh J, Shin JE, Yang KH, et al. Cortical and subcortical changes in resting-state functional connectivity before and during an episode of postoperative delirium. Aust N Z J Psychiatry. 2019;53:794-806.

99. Choi S-H, Lee H, Chung T-S, et al. Neural network functional connectivity during and after an episode of delirium. Am J Psychiatry. 2012:169:498-507.

100. van Montfort SJT, van Dellen E, Stam CJ, et al. Brain network disintegration as a final common pathway for delirium: a systematic review and qualitative meta-analysis. Neurolmage Clin. 2019;23:101809.

101. Sanabria-Diaz G, Martínez-Montes E, Melie-Garcia L, et al. Glucose metabolism during resting state reveals abnormal brain networks organization in the Alzheimer's disease and mild cognitive impairment. PLOS ONE. 2013;8:e68860-e68860.

102. Buckner RL, Vincent JL. Unrest at rest: default activity and spontaneous network correlations. Neuroimage. 2007;37:1091-9.

103. Trogrlić Z, van der Jagt M, Bakker J, et al. A systematic review of implementation strategies for assessment, prevention, and management of ICU delirium and their effect on clinical outcomes. Crit Care. 2015:19:157.

104. SIGN (Scottish Intercollegiate Guidelines Network). Risk reduction and management of delirium: a national clinical guideline. 157, https:// www.sign.ac.uk/media/1423/sign157.pdf. Accessed 15 Nov 2020

105. Bannon L, McGaughey J, Verghis R, et al. The effectiveness of non-pharmacological interventions in reducing the incidence and duration of delirium in critically ill patients: a systematic review and meta-analysis. Intensive Care Med. 2019;45:1-12.

106. Page VJ, Ely EW, Gates S, et al. Effect of intravenous haloperidol on the duration of delirium and coma in critically ill patients (Hope-ICU): a randomised, double-blind, placebo-controlled trial. Lancet Respir Med. 2013:1:515-23.

107. Heijnen NFL, Bergmans DCJJ, Schnabel RM, et al. Targeted treatment of acute respiratory distress syndrome with statins-a commentary on two phenotype stratified re-analysis of randomized controlled trials. J Thorac Dis. 2019;11:S296-9.

108. Calfee CS, Delucchi KL, Sinha P, et al. Acute respiratory distress syndrome subphenotypes and differential response to simvastatin: secondary analysis of a randomised controlled trial. Lancet Respir Med. 2018:6:691-8.

109. Calfee CS, Delucchi K, Parsons PE, et al. Subphenotypes in acute respiratory distress syndrome: latent class analysis of data from two randomised controlled trials. Lancet Respir Med. 2014;2:611-20. 
110. Famous KR, Delucchi K, Ware LB, et al. Acute respiratory distress syndrome subphenotypes respond differently to randomized fluid management strategy. Am J Respir Crit Care Med. 2017;195:331-8.

111. Frades I, Matthiesen R. Overview on techniques in cluster analysis. Methods Mol Biol. 2010;593:81-107.

112. Makris K, Spanou L. Acute kidney injury: definition, pathophysiology and clinical phenotypes. Clin Biochem Rev. 2016;37:85-98.

113. Bos LD, Schouten $L R$, van Vught LA, et al. Identification and validation of distinct biological phenotypes in patients with acute respiratory distress syndrome by cluster analysis. Thorax. 2017;72:876-83.

114. Delucchi K, Famous KR, Ware LB, et al. Stability of ARDS subphenotypes over time in two randomised controlled trials. Thorax. 2018;73:439-45.

115. Charlson ME, Pompei $P$, Ales $K L$, et al. A new method of classifying prognostic comorbidity in longitudinal studies: development and validation. J Chronic Dis. 1987;40:373-83.

116. Roso-Llorach A, Violán C, Foguet-Boreu Q, et al. Comparative analysis of methods for identifying multimorbidity patterns: a study of 'real-world' data. BMJ Open. 2018;8:e018986.

117. Briongos-Figuero LS, Cobos-Siles M, Gabella-Martín M, et al. Evaluation and characterization of multimorbidity profiles, resource consumption and healthcare needs in extremely elderly people. Int J Qual Heal Care. 2020;32:266-70.

118. Davis DHJ, Kreisel SH, Muniz Terrera G, et al. The epidemiology of delirium: challenges and opportunities for population studies. Am J Geriatr Psychiatry. 2013;21:1173-89.

119. Casey P, Cross W, Mart MW-S, et al. Hospital discharge data underreports delirium occurrence: results from a point prevalence survey of delirium in a major Australian health service. Intern Med J. 2019;49:338-44.

120. Hashem MD, Hopkins RO, Colantuoni E, et al. Six-month and 12-month patient outcomes based on inflammatory subphenotypes in sepsisassociated ARDS: secondary analysis of SAILS-ALTOS trial. Thorax. 2021. https://doi.org/10.1136/thoraxjnl-2020-216613.

\section{Publisher's Note}

Springer Nature remains neutral with regard to jurisdictional claims in published maps and institutional affiliations.
Ready to submit your research? Choose BMC and benefit from:

- fast, convenient online submission

- thorough peer review by experienced researchers in your field

- rapid publication on acceptance

- support for research data, including large and complex data types

- gold Open Access which fosters wider collaboration and increased citations

- maximum visibility for your research: over 100M website views per year

At BMC, research is always in progress.

Learn more biomedcentral.com/submissions 